\title{
Role of selenium and glutathione peroxidase on development, growth, and oxidative balance in rat offspring
}

\author{
Fátima Nogales, M Luisa Ojeda, María Fenutría, M Luisa Murillo and Olimpia Carreras \\ Department of Physiology, Faculty of Pharmacy, Seville University, C/Profesor García Gonzalez, \\ No. 2, 41012 Seville, Spain \\ Correspondence should be addressed to O Carreras; Email: olimpia@us.es
}

\begin{abstract}
Selenium (Se), an essential trace metal, is important in both growth and reproduction and is the constituent of different selenoproteins. The glutathione peroxidase (GPx) family is the most studied as it prevents oxidative stress. Liver oxidation is considered as another mechanism involved in low birth weight. Therefore, in order to ascertain whether GPx is related to the effects of Se on growth during gestation and lactation, three groups of rat pups were used: control, Se deficient (SD), and Se supplemented (SS). Morphological parameters and reproductive indices were evaluated. Hepatic Se levels were measured by graphite furnace atomic absorption while spectrophotometry was used for activity of antioxidant enzymes and oxidative stress markers in liver and western blotting for expression of hepatic GPx1 and GPx4. The SD diet increased mortality at birth; decreased viability and survival indices; and stunted growth, length, and liver development in offspring, thus decreasing hepatic Se levels, GPx, glutathione reductase, and catalase activities, while increasing superoxide dismutase activity and protein oxidation. The SS diet counteracted all the above results. GPx1 expression was heavily regulated by Se dietary intake; however, although Se dietary deficiency reduced GPx4 expression, this decrease was not as pronounced. Therefore, it can be concluded that Se dietary intake is intimately related to growth, length, and directly regulating GPx activity primarily via GPx1 and secondly to GPx4, thus affecting liver oxidation and development. These results suggest that if risk of uterine growth retardation is suspected, or if a neonate with low birth weight presents with signs of liver oxidation, it may be beneficial to know about Se status.

Reproduction (2013) 146 659-667
\end{abstract}

\section{Introduction}

Selenium (Se) is an essential trace metal with beneficial properties and is principally known for its antioxidant capacity, which protects cell from free radicals (Parízek 1990). The biological effectiveness of Se is based upon the integration of selenocysteine (as the 21st amino acid) into the active center of 25 selenoproteins with biological properties. Among these selenoproteins, the glutathione peroxidase (GPx) family is the most studied and is involved in regulating oxidative processes and cell membrane protection (Papp et al. 2007), as these selenoenzymes catalyze the reduction of hydroperoxides and lipid peroxides to their corresponding alcohols and water with reduced glutathione $(\mathrm{GSH})$ as the electron donor (Brigelius-Flohé \& Maiorino 2013).

Se has multiple functions in the organism; therefore, Se deficiency can lead to a number of physiological disorders in humans and animals. Increasing evidence suggests that this mineral also plays an important role in normal growth and reproduction (Mistry et al. 2012). In this context, Se has been related to somatic growth regulation, influencing 3,5,3'-triiodothyronine $\left(\mathrm{T}_{3}\right)$ and the growth hormone $(\mathrm{GH})$-insulin-like growth factor (IGF) axis (Moreno-Reyes et al. 2001). He et al. (2006) have reported that a Se deficiency depresses growth by decreasing the activity of the selenoprotein iodothyronine 5'-deiodinase in liver, causing a decrease in the plasma concentration of $T_{3}$ and protein turnover. It is suggested that Se is particularly important for IGF bioactivity (Karl et al. 2009). However, whether Se intake is important for IGF biological activity has not been studied extensively, despite the relationship between $\mathrm{T}_{3}$ and the hypothalamic-GH-IGF axis (Miell et al. 1993). An association between low Se intake and low IGF1 serum values in adults and children has been reported (Aydin et al. 2002, Maggio et al. 2010), yet Se supplementation in gestating ruminants does not affect IGF1 concentration in their offspring (Ward et al. 2008, Gunter et al. 2013).

Several studies have suggested oxidative stress as another agent responsible for impaired reproductive function and intrauterine growth retardation (Biri et al. 2007, Hracsko et al. 2008, Pathak et al. 2011, Mistry et al. 2012) by the oxidation of protein, lipids, and DNA, preventing a normal metabolism of these elements, 
which in turn leads to a disrupted tissue metabolism. This oxidation is especially harmful during gestation and lactation when the cell membrane proteins are developing. Se is essential for GPx antioxidant activity, preventing the oxidation of the membranes' lipids and proteins (Hefnawy \& Tortora-Pérez 2010). Therefore, dams' dietary Se intake during gestation and lactation could alter GPx activity and oxidative balance (Turło et al. 2010) in offspring, which in turn could be related to changes in offspring growth and length at birth, as well as at the end of lactation.

Taking into account that the liver is the main metabolic organ for processing, distributing, and supplying nutrients, as well as releasing IGF to blood, any damage, including oxidation, to this tissue will have an impact on the organism's development. In fact, in vitro studies on hepatocytes have found a relationship between GH and IGF1 on GPx activity and antioxidant regulation (Brown-Borg et al. 2002). The main objective of this research, therefore, was to study the role of dams' dietary Se intake in the development and growth of offspring during gestation and lactation, analyzing its effect in liver GPx activity and expression and therefore in the oxidative balance as another factor concomitant to correct body development.

\section{Materials and methods}

\section{Animals and samples}

Male and female Wistar rats (Centre of Production and Animal experimentation, Vice-rector's Office for Scientific Research, University of Seville) weighing 150-200 g were randomized into three groups: control (C), Se deficient (SD), and Se supplemented (SS). Drinking water and diet (deficient, control, or supplemented) were given ad libitum during the pre-gestation ( 7 weeks), gestation (3 weeks), and lactation (3 weeks) periods. In the week following the pre-gestational period, male $(n=3)$ and female $(n=6)$ rats were mated to obtain the first-generation offspring for each group. Pregnant female rats were inspected daily by the presence of the vaginal plug, which indicated day 0 of pregnancy; at this moment, pregnant rats were housed individually in plastic cages. The day of parturition, which occurs spontaneously 3 weeks after coitus, was designated as day 1 of lactation. The offspring number was reduced to eight per mother at parturition. The experiments were performed on the offspring of all the three groups 21 days post-partum. In this study, we have used eight pups per group to measure all the parameters cited below. These eight pups represent all the litters, as a maximum of two rats per litter, and were allocated to each group taking into account the sex (when this was possible).

The animals were kept at an automatically controlled temperature $\left(22-23^{\circ} \mathrm{C}\right)$ and a $12 \mathrm{~h}$ light: $12 \mathrm{~h}$ darkness cycle (0900-2100 h). Animal care was complied with the Guide for the Care and Use of Laboratory Animals (National Academy Press, Washington, DC, 1996).
The diets of these rats were prepared according to The Council of the Institute of Laboratory Animal Resources (ILAR 1979), which details known nutrient requirements for most of the common laboratory animals. The diet of the $\mathrm{C}$ group contained 0.1 p.p.m. of Se while the SD and SS group diets contained 0.01 and 0.5 p.p.m. of Se respectively. Se was supplemented as anhydrous sodium selenite (an inorganic compound; Panreac, Barcelona, Spain).

The amount of energy consumed (kcal) by dams was estimated by measuring the amount of food consumed by day and multiplying by $3.96 \mathrm{kcal}$. Se intake was calculated by multiplying the food consumed by p.p.m. of Se in the diets.

Weekly body weight of dams and their pups was controlled until the end of the experimental period. Additionally, cranialcaudal length of pups was measured using a metric caliper. All measures were taken at $0900 \mathrm{~h}$ to avoid changes due to circadian rhythms.

At the end of the experimental period, dams and their pups were fasted for $12 \mathrm{~h}$, and feces and urine samples were collected using individual metabolic cages. After that, rats were anesthetized with i.p. $28 \% \mathrm{w} / \mathrm{v}$ urethane $(0.5 \mathrm{ml} / 100 \mathrm{~g}$ of body weight). Blood samples were obtained by heart puncture and collected in tubes. The serum was prepared using low-speed centrifugation for $15 \mathrm{~min}$ at $1300 \mathrm{~g}$. The abdomen was opened by a midline incision and whole livers were removed, debrided of adipose and connective tissues in ice-cold saline, weighed, and stored at $-80{ }^{\circ} \mathrm{C}$ prior to biochemical determinations.

The amount of milk consumed by the offspring at the end of the lactation period (days 19 and 20) was estimated by subtracting the weight of the pups obtained immediately prior to returning them to the dam from their weight after 30 min of suckling (Subramanian 1995). In order to obtain the maximum amount of milk at day 21 of lactation, $3 \mathrm{~h}$ after removing the litters from their mothers, the dams were anesthetized with urethane and milk samples were immediately collected. The milk was obtained by gently massaging the area around each of the 12 mammary glands and then pressing upward from the base of the gland toward the nipple. The amount of milk collected was around $1-1.5 \mathrm{ml} / \mathrm{dam}$.

Gestational and lactation indexes were calculated as follows: female fertility index was calculated as number of pregnancies/ number of mating $\times 100$; gestational index as number of successful births/number of pregnancies rats $\times 100$; and liveborn index as number of pups born alive/number of pups born $\times 100$. Viability index was calculated as number of pups alive on day $7 /$ number of pups alive and kept on day $4 \times 100$; weaning index (WI) as number of pups alive at day $21 /$ number of pups alive and kept on day $4 \times 100$; and lactation survival index (LSI) as (number of total offspring-number of dead offspring/number of total offspring) $\times 100$.

\section{Se analysis}

Se levels were determined by graphite furnace atomic absorption spectrometry, using a PerkinElmer AAnalyst 800 high-performance atomic absorption spectrometer with WinLab32 for AA Software, equipped with a Transversely Heated Graphite Furnace (THGA) with longitudinal Zeeman effect background corrector and an AS-furnace autosampler 
(PerkinElmer, Überlingen, Germany). The source of radiation was a Se electrodeless discharge lamp. The instrumental operating conditions and the reagents are the same as those we used in the previous paper by Ojeda et al. (2009). Samples: serum samples were diluted fivefold in $0.2 \% \mathrm{v} / \mathrm{v} \mathrm{HNO}_{3}$ and $0.2 \%$ Triton $\mathrm{X}-100$ solutions and urine samples were diluted $1: 2 \mathrm{v} / \mathrm{v}$. After $72 \mathrm{~h}$ at $100{ }^{\circ} \mathrm{C}$ dry temperature, feces and milk samples were weighed and digested in a sand bath heater (OVAN, Badalona, Spain) with nitric acid for $72 \mathrm{~h}$, and perchloric acid and hydrochloric acid $(6 \mathrm{M})$ were added. The accuracy of the method has been confirmed using CertiPUR Selenium AA Single Element Standard of National Institute of Standards and Technology and Technology Standard Reference Material (NIST-SRM). The linear concentration range of the calibration curve was 5-100 $\mu \mathrm{g} / \mathrm{l}$, with a correlation coefficient of 0.996 . The analytical coefficient of variation (CV) was calculated from the values obtained by measuring the same control at $100 \mu \mathrm{g} / \mathrm{l}$ with each batch of specimens analyzed. The $\mathrm{CV}$ of the measurements was of 0.021 , the limit of detection was $0.2 \mathrm{ng} / \mathrm{l}$, and the repeatability was of $7.1 \%$.

\section{Biochemical analysis: antioxidant enzymes and oxidative stress markers}

In order to measure the activity of antioxidant enzymes as well as the oxidation of lipids and proteins, liver tissue samples were homogenized (100 g for $1 \mathrm{~min}, 1: 10 \mathrm{w} / \mathrm{v}$; Pobel 245432, Madrid, Spain) in a sucrose buffer $(15 \mathrm{mM}$ Tris/ $\mathrm{HCl}, \mathrm{pH} 7.4$, $250 \mathrm{mM}$ sucrose, $1 \mathrm{mM}$ EDTA, and $1 \mathrm{mM}$ dithiothreitol) in an ice bath. The homogenate was centrifuged at $900 \mathrm{~g}$ for $10 \mathrm{~min}$ at $4{ }^{\circ} \mathrm{C}$. The resulting supernatant was employed for the biochemical assay. GPx activity was determined by the method of Lawrence \& Burk (1976), in which GPx catalyzes the oxidation of GSH by hydrogen peroxide. The catalase (CAT), glutathione reductase (GR), and superoxide dismutase (SOD) activities were determined using the methods of Beers \& Sizer (1952), Worthington \& Rosemeyer (1974), and Fridovich (1985) respectively. Lipid peroxidation was evaluated by the method based on the reaction between malondialdehyde (MDA) and thiobarbituric acid (Draper \& Hadley 1990). Hepatic protein oxidation was measured according to a method based on the spectrophotometric detection of the reaction of 2,4-dinitrophenylhydrazine with protein carbonyl (PC) to form protein hydrazones (Reznick \& Packer 1994). The protein content of the samples was determined by the method of Lowry et al. (1951), using BSA as the standard.

\section{Selenoprotein immunoblotting assays}

The expression of the hepatic selenoproteins GPx1 and GPx4 in pups was conducted using the Laemmli method (1970). The samples utilized contained $75 \mu \mathrm{g}$ protein. Proteins were separated on polyacrylamide gel and transferred onto a nitrocellulose membrane (Immobilon-P Transfer Membrane, Millipore, Billerica, MA, USA) using a blot system (Transblot, Bio-Rad). Membrane nonspecific sites were blocked during $1 \mathrm{~h}$ with blocking buffer: TTBS $(50 \mathrm{mM}$ Tris- $\mathrm{HCl}, 150 \mathrm{mM} \mathrm{NaCl}$, and $0.1 \%(\mathrm{v} / \mathrm{v})$ Tween 20, $\mathrm{pH} 7.5)$ and milk powder 3\% (Bio$\mathrm{Rad})$, and thereafter, they were probed overnight at $4{ }^{\circ} \mathrm{C}$ with specific primary antibodies (rabbit polyclonal IgG, Santa Cruz Biotechnology), dilutions: GPx1 (1:20 000) and GPx4 (1:5000). Subsequently, secondary antibody (anti-rabbit IgG HRP conjugate, Santa Cruz Biotechnology) was utilized in dilutions of 1:5000. Monoclonal mouse anti- $\beta$-actin (IgG1 A5441, Sigma-Aldrich) was used to detect $\beta$-actin, as a loading control, with a dilution of 1:40 000, and a secondary antibody anti-mouse IgG peroxidase conjugate (A9044, Sigma-Aldrich) was used in a dilution of $1: 8000$. The membrane was incubated for $1 \mathrm{~min}$ with the commercial developer solution Luminol ECL reagent (GE Health Care and Lumigen, Inc., Buckinghamshire, UK). The quantification of the blots was performed by densitometry with PCBAS 2.08e Software analysis (Raytest, Inc., Straubenhardt, Germany). The results were expressed as percent arbitrary relative units referred to values in control pups that were defined as $100 \%$.

\section{Statistical analysis}

The results are expressed as means \pm s.E.M. The data were analyzed using a statistical program (GraphPad InStat 3, San Diego, CA, USA) by ANOVA (one-way ANOVA). The statistical significance was established at $P<0.05$. When ANOVA resulted in differences, multiple comparisons between means were studied by the Tukey-Kramer test.

\section{Results and discussion \\ Gestational parameters}

In our Se deficiency model, no alteration in reproductive performance was found, except for a slight reduction in the live-birth index (Table 1). Ramirez et al. (2001) hypothesized that dietary Se deficiency in dairy goat kids could be considered a risk of perinatal mortality of kids ( $0-7$ days), which had an extremely low weight. Our results showed that Se deficiency in dams did not compromise reproductive success as all the rat crosses were fertile and all the pregnancies carried to term. Furthermore, all the dams gave birth within the usual expected 21-day gestation period and there were no significant changes in the number of pups per litter. However, although the calorie intake of the three groups was similar during gestation, the body weights and lengths of their offspring were significantly different (Table 1). Therefore, the effects observed could only be attributed to the dams' Se intake. In this context, dietary Se deficiency causes intrauterine growth retardation, as pups showed a lower birth body weight and cranialcaudal length. By contrast, a SS diet significantly increased birth body weight and cranial-caudal length compared with $\mathrm{C}$ pups. These results are in agreement with the available bibliography cited that points to Se deficiency as a key factor on somatic growth retardation, via $\mathrm{T}_{3}$ and IGF (Moreno-Reyes et al. 2001). However in our model, Se supplementation also activated somatic growth. In this context, Rayman (2012) has also reported that a higher Se status has antiviral effects and is essential 
Table 1 Gestational parameters in dams and offspring.

\begin{tabular}{lccc}
\hline & C & SS & SD \\
\hline Dam energy intake (kcal/day) & $75.8 \pm 5.8$ & $79.6 \pm 5.6$ & $86.32 \pm 7.3$ \\
Dam Se intake ( $\mu$ g/day) & $1.89 \pm 0.09$ & $9.95 \pm 0.10^{*}$ & $0.24 \pm 0.02^{+, \S}$ \\
FFI (\%) & 100 & 100 & 100 \\
Gl (\%) & 100 & 100 & 100 \\
LBI (\%) & 100 & 100 & 95.91 \\
No. of offspring per litter & $11.0 \pm 0.5$ & $13.0 \pm 0.6$ & $12.25 \pm 1.1$ \\
No. of offspring survival & $11.0 \pm 0.5$ & $13.0 \pm 0.6$ & $11.25 \pm 0.6$ \\
Offspring weight at birth (g) & $5.7 \pm 0.10$ & $7.0 \pm 0.31^{*}$ & $4.7 \pm 0.08^{+, \S}$ \\
Offspring cranial-caudal length at birth $(\mathrm{cm})$ & $4.91 \pm 0.08$ & $5.74 \pm 0.12^{*}$ & $4.58 \pm 0.05^{\ddagger, \S}$ \\
\hline
\end{tabular}

The results are expressed as mean \pm S.E.M. and analyzed by a multifactorial ANOVA (one-way ANOVA) followed by the Tukey's test. The number of animals in each group is 8. Groups: C, control group; SS, Se supplemented group; SD, Se deficient group. Signification: $C$ vs SS, ${ }^{*} P<0.001 ; C$ vs SD, ${ }^{\dagger} P<0.001,{ }^{\ddagger} P<0.01$; SS vs SD, ${ }^{\$} P<0.001$. Female fertility index (FFI) was calculated as number of pregnancies/number of mating $\times 100$; gestational index $(\mathrm{Gl})$ as number of successful births/number of pregnancies rats $\times 100$; and live-born index $(\mathrm{LBI})$ as number of pups born alive/number of pups born $\times 100$.

for successful male and female reproduction, as well as reducing the risk of autoimmune thyroid disease. According to the data obtained, Mistry et al. (2012) found that low plasma Se concentration could contribute to growth retardation, possibly by lowering the placental antioxidant defense because, as it is well know, Se is a cofactor of the antioxidant enzyme GPx. In preliminary unpublished studies of our research group, we have found that an increase in Se in dams' diet could improve GPx placenta activity and oxidative balance.

\section{Lactation parameters}

During the lactation period, dams showed evident differences in energy intake. Therefore, both SD and SS rats showed a significantly higher energy intake than $\mathrm{C}$ ones (Table 2). Se intake was eight times higher in SS dams vs $\mathrm{C}$ ones and six times lower in SD with respect to $C$. However, when milk Se levels were analyzed, there were no differences between SS and C dams while SD presented the lowest Se content. This decrease, however, was not proportional to Se intake, as the decrease in Se levels was less pronounced. It could be suggested that despite the fact that the dams consumed different amounts of Se, they tried to reduce these differences by sacrificing their own demands in order to provide their offspring with a correct amount of Se via milk. These results are in agreement with those reported by $\mathrm{Abd}$ El-Ghany et al. (2008) in ruminants.

When serum Se levels were analyzed in pups (Table 2), the SS group had the highest value, while SD and $C$ pups had similar amounts of Se in serum. This should be because, Se stored in tissues could be utilized to maintain plasma GPx activity during periods of low Se intake (Payne \& Southern 2005).

At the end of lactation, SD offspring showed the lowest weight and cranial-caudal length and SS pups the highest weight (Table 2). This lower development in SD pups was a consequence of both the restriction in fetal growth observed at birth and the Se deficiency presented during lactation because despite consuming the same amount of milk as the rest of the groups, this milk's Se content was significantly lower. These results demonstrated that dams' low dietary Se intake affects offspring development and growth during pre- and postnatal life and, that, according to Hefnawy \& Tortora-Pérez (2010), abnormally low Se values can cause serious growth disorders. Our results also demonstrated that a SD diet

Table 2 Lactation parameters in dams and offspring.

\begin{tabular}{|c|c|c|c|}
\hline & C & SS & SD \\
\hline Dam energy intake (kcal/day) & $124.9 \pm 12.3$ & $191.2 \pm 15.4^{*}$ & $211.7 \pm 16.8^{\S}$ \\
\hline Dam Se intake ( $\mu \mathrm{g} /$ day) & $3.1 \pm 0.31$ & $23.9 \pm 2.01^{\dagger}$ & $0.53 \pm 0.03^{\S, \boldsymbol{I}}$ \\
\hline $\mathrm{VI}(\%)$ & 100 & 100 & 89.79 \\
\hline WI $(\%)$ & 100 & 100 & 100 \\
\hline LSI (\%) & 100 & 100 & 89.79 \\
\hline Offspring weight at 21 days (g) & $32.4 \pm 1.24$ & $37.5 \pm 1.85^{\neq}$ & $23.2 \pm 0.55^{\S, \mathbb{1}}$ \\
\hline Offspring cranial-caudal length at 21 days $(\mathrm{cm})$ & $10.37 \pm 0.21$ & $10.76 \pm 0.42$ & $8.95 \pm 0.29^{\S, 9}$ \\
\hline Milk intake in 30 suckling $(\mu \mathrm{l} / \mathrm{g})$ & $16.97 \pm 0.8$ & $16.88 \pm 1.2$ & $16.59 \pm 1.0$ \\
\hline Se in milk $(\mu g / g)$ & $0.124 \pm 0.005$ & $0.126 \pm 0.003$ & $0.102 \pm 0.003^{11, \mathrm{a}}$ \\
\hline Se in serum $(\mu \mathrm{g} / \mathrm{l})$ & $114.06 \pm 3.1$ & $109.75 \pm 3.9$ & $217.19 \pm 3.74^{\text {\$, }}$ \\
\hline
\end{tabular}

The results are expressed as mean \pm s.E.M. and analyzed by a multifactorial ANOVA (one-way ANOVA) followed by the Tukey's test. The number of animals in each group is 8. Groups: C, control group; SS, Se supplemented group; SD, Se deficient group. Signification: C vs SS: ${ }^{*} P<0.001,{ }^{\dagger} P<0.01,{ }^{\ddagger} P<0.05$; C vs SD: ${ }^{5} P<0.001,{ }^{\|} P<0.01$; SD vs SS: ${ }^{\sharp} P<0.001,{ }^{a} P<0.01$. Viability index (VI) was calculated as number of pups alive on day $7 /$ number of pups alive and kept on day $4 \times 100$; WI as number of pups alive at day 21 /number of pup alive and kept on day $4 \times 100$; and LSI as (number of total offspring-number of dead offspring/number of total offspring) $\times 100$. 
significantly decreased the viability and the LSIs while it did not affect the WI (Table 2), causing serious damage in some offspring that died during the first week of life. Therefore, at this stage of life, Se deficiency is not only linked to growth retardation but also to mortality. In the same context, and corroborating the effects of a low Se supply on growth during gestation and lactation, a correct Se supplementation in dams promotes development in fetuses and pups, improving the lactation parameters measured. The experimental design used in this work demonstrates that a low dams' dietary Se intake during gestation and lactation is directly related to offspring development. Knowledge of the Se status in women with a risk of uterine growth retardation or in neonates with low birth weight may be beneficial for them. However, during lactation, the parameters for pup weight and cranial-caudal length in the SS group tend to approach to the control values. Therefore, the Se supplementation used in this experiment seems to mainly affect the development of pups during gestation.

Finally, when liver development was analyzed (Table 3), at the end of the lactation period, SS and C pups had similar liver weights in relation to their body weight and protein content. However, SD pups had a lower liver weight and lower protein content, evidence of an underdeveloped liver.

\section{Antioxidative defense and oxidative stress markers in liver}

As was expected, Se liver deposits at the end of lactation (Fig. 1) were significantly lower in SD pups and higher in SS ones with respect to $C$ pups. However, the repletion found in SS pups was lower than that expected. These results support the work of Sunde \& Raines (2011) who found a sigmoidal response with a plateau in liver Se deposits in weaning rats fed with different amounts of Se (0.08-0.24 $\mu \mathrm{g} \mathrm{Se/g} \mathrm{diet).} \mathrm{This} \mathrm{Se} \mathrm{content} \mathrm{in} \mathrm{liver} \mathrm{is}$ related to its developmental state. In accordance with these data, GPx activity and Se levels in liver decreased analogously in SD pups and increased at a similar rate in SS pups. This direct relationship between Se and GPx

Table 3 Hepatic morphological parameters in offspring.

\begin{tabular}{lccc}
\hline & C & SS & SD \\
\hline Liver weight (g) & $1.20 \pm 0.03$ & $1.48 \pm 0.04^{*}$ & $0.79 \pm 0.01^{+, \|}$ \\
Relative liver & $3.7 \pm 0.1$ & $3.94 \pm 0.09$ & $3.40 \pm 0.05^{\ddagger, \|}$ \\
$\quad$ weight (g/g body & & & \\
$\quad \begin{array}{l}\text { weight (\%)) } \\
\text { Protein (mg/g liver } \\
\quad \text { wet tissue) }\end{array}$ & $103.18 \pm 3.48$ & $108.61 \pm 5.15$ & $92.52 \pm 3.68^{\text {§, I }}$ \\
\hline
\end{tabular}

The results are expressed as mean \pm S.E.M. and analyzed by a multifactorial ANOVA (one-way AN̄OVA) followed by the Tukey's test. The number of animals in each group is 8 . Groups: $\mathrm{C}$, Control group; SS, Se supplemented group; SD, Se deficient group. Signification: C vs SS: ${ }^{*} P<0.001 ; C$ vs SD: ${ }^{\dagger} P<0.001,{ }^{\ddagger} P<0.01,{ }^{\$} P<0.05 ;$ SD vs SS: $\| P<0.001, " P<0.05$.

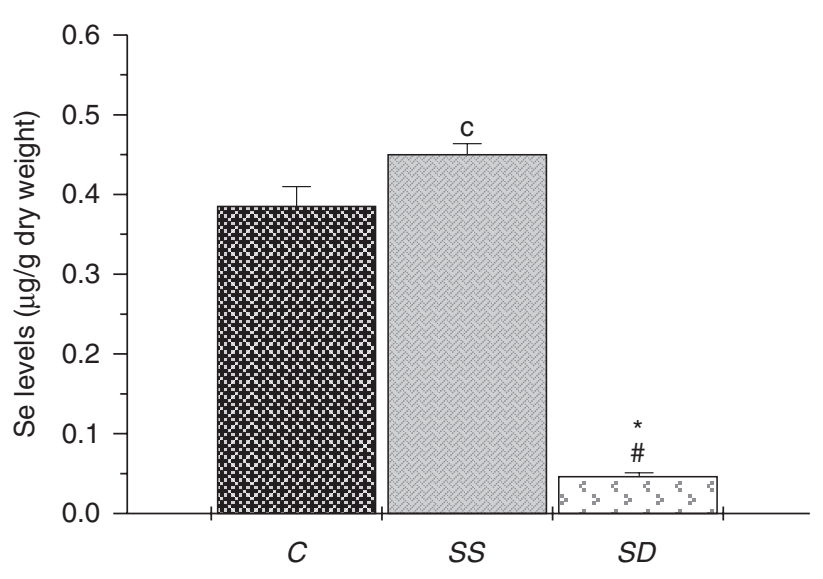

Figure 1 Hepatic Se levels ( $\mu \mathrm{g} / \mathrm{g}$ dry weight) in offspring. The results are expressed as mean \pm S.E.M. and analyzed by a multifactorial ANOVA (one-way ANOVA) followed by the Tukey's test. The number of animals in each group is 8. Groups: C, control group; SS, Se supplemented group; $\mathrm{SD}$, Se deficient group. Significance: $\mathrm{C}$ vs $\mathrm{SS},{ }^{\mathrm{c}} P<0.05 ; \mathrm{C}$ vs $\mathrm{SD}$, ${ }^{*} P<0.001 ;$ SS vs SD, ${ }^{\#} P<0.001$.

activity in liver was also found by other authors in different tissues (Agay et al. 2005, Ojeda et al. 2012).

In order to investigate whether the pups exposed to different Se intake show alterations in liver antioxidant enzyme activities, a reduction in GR and CAT activity was observed in SD offspring while SOD was greatly enhanced when compared with C pups (Fig. 2). Simultaneously, MDA and PC levels were determined as markers of oxidative stress in liver (Fig. 3). No changes in MDA concentrations were observed in the three groups studied, yet PC levels that resulted in higher protein liver oxidation were significantly higher in the SD group. This induced oxidation indicates that normal protein metabolism was disrupted, resulting in an accumulation of damaged molecules. The protein oxidation is probably due to the remarkable increase in SOD activity. Despite the fact that this is the most important enzyme attenuating free radical-induced oxidative damage, it is acting jointly with inhibited GPx and CAT enzymes that do not fight against the SODgenerated $\mathrm{H}_{2} \mathrm{O}_{2}$ (Agay et al. 2005). This SOD overactivation leads to an accumulation of $\mathrm{H}_{2} \mathrm{O}_{2}$, which in the absence of GPx and CAT activities increases Fenton reactions, producing protein oxidation in liver. Therefore, there is a clear relationship between Se deficiency, GPx activity, and protein oxidation in liver, which is also parallel to low liver development. This increase in SOD activity in conditions of Se deficiency has also been detected by other authors in mouse liver (Stỳblo et al. 2007), as well as in other tissues (Sirota 2010, Erkekoglu et al. 2012). This increase in SOD activity could be to compensate the formation of more superoxide generated by mitochondrial dysfunction, caused in part by the increase in reactive oxygen species (ROS; Shi et al. 2012), by the decrease in Se levels that are related to a correct mitochondrial function and its biogenesis (Mehta 


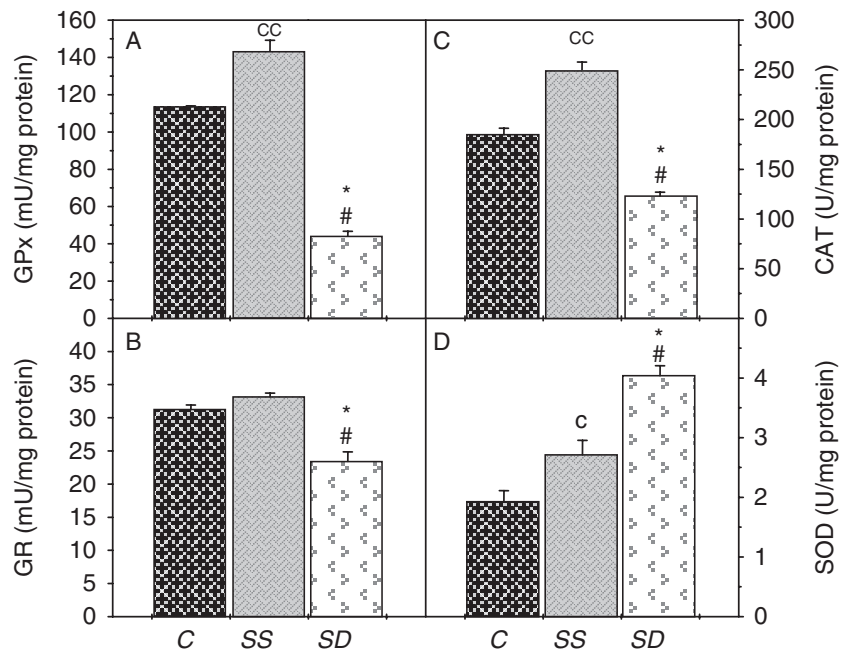

Figure 2 Activity of hepatic antioxidant enzymes in offspring: GPx (A), GR (B), CAT (C), and SOD (D). The results are expressed as mean \pm S.E.M. and analyzed by a multifactorial ANOVA (one-way ANOVA) followed by the Tukey's test. The number of animals in each group is 8 . Groups: C, control group, SS, Se supplemented group, SD, Se deficient group. Significance: $C$ vs SS: ${ }^{c c} P<0.001,{ }^{c} P<0.05$; $C$ vs SD: ${ }^{*} P<0.001$; SS vs SD, ${ }^{*} P<0.001$.

et al. 2012, Wang et al. 2013), or by the decrease in GPx4 expression found in liver, which has a major role in protecting mitochondria from oxidative damage (Cole-Ezea et al. 2012).

Dietary Se supplementation in dams counteracts the effects of a Se deficiency, significantly increasing the activity of pups' GPx, GR, and CAT while decreasing SOD activity when compared with SD pups. Comparing these activities with those in controls, increases in the activities of GPx and CAT were proportional to increase in SOD observed. Therefore, the $\mathrm{H}_{2} \mathrm{O}_{2}$ formed by SOD was successfully removed by the latter two enzymes while no liver oxidation was found. Ahmad et al. (2012) also described an increase in CAT and SOD activities after Se supplementation in adult chickens, explaining this effect as being an overexpression of the selenoprotein iodothyronine deiodinase leading to high levels of $\mathrm{T}_{3}$, which are closely related to ROS production. This upregulation of the antioxidant activity generated by Se supplementation is an efficient manner of allowing hyperactivity of the thyroid axis without oxidative damage, enabling correct development. This stimulation of the antioxidant activity could also be related to the effects of GH and IGF over the hepatocytes in vitro (Aksu et al. 2013) and in vivo (Brown-Borg et al. 2002), appearing to increase oxidation and decrease GPx activity when they act as somatic growth inductors. Therefore, it might point out that Se and GPx, among other selenoproteins, play a role in correct liver development, preventing concomitant oxidation.

Finally, as GSH is the main intracellular endogenous antioxidant molecule (Avanzo et al. 2001), the ratio of reduced glutathione oxidized glutathione (GSH:GSSG) was measured as an indicator of oxidative stress (Fig. 4). A significant decrease in GSH:GSSG ratio was evident in the SD group when compared with $\mathrm{C}$ pups. However, Se supplementation increases this value - it is even higher than in $\mathrm{C}$ pups. This decreased ratio in SD pups is mainly due to an increase in GSSG $(0.023 \pm 0.004 \mu \mathrm{mol} / \mathrm{g}$ tissue) when compared with $C(0.011 \pm 0.0015 \mu \mathrm{mol} / \mathrm{g}$ tissue) and supplemented ( $0.007 \pm 0.0006 \mu \mathrm{mol} / \mathrm{g}$ tissue $)$ groups. This might be due to the overproduction of $\mathrm{H}_{2} \mathrm{O}_{2}$ provoked by SOD activity, which promotes the Fenton reaction and enhances oxidation.

By contrast, Se supplementation increased the GSH:GSSG ratio with respect to $C$ pups. These results are in agreement with several studies that have indicated that Se supplementation can enhance GSH concentrations and decrease concentrations of its oxidized products (GSSG) in tissues and blood (Hoffman 2002, Richie et al. 2012). Therefore, Se supplementation to dams during gestation and lactation prevents oxidative stress in their pups' liver as it increases antioxidant enzyme activities and improves the GSH:GSSG ratio. In conclusion, Se supplementation could be proposed as an antioxidant therapy during pregnancy and lactation

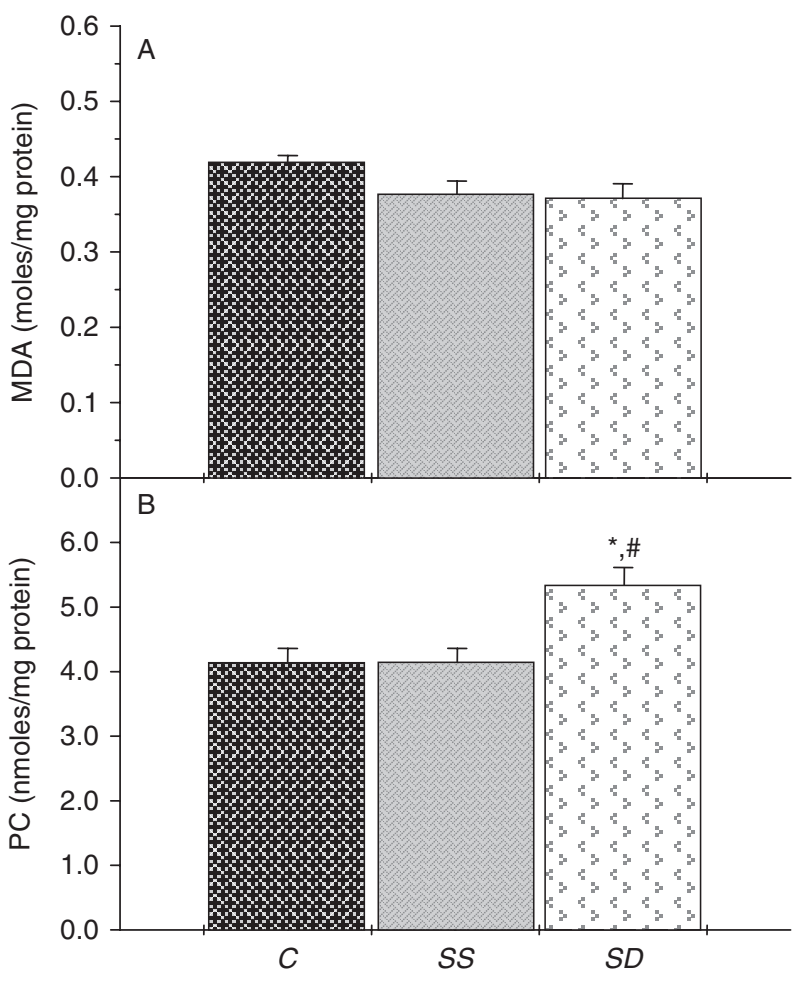

Figure 3 Hepatic oxidation in offspring: levels of MDA ( $\mathrm{mol} / \mathrm{mg}$ protein) in lipid (A) and PC (nmol/mg protein); (B). The results are expressed as mean \pm s.E.M. and analyzed by a multifactorial ANOVA (one-way ANOVA) followed by the Tukey's test. The number of animals in each group is 8. Groups: C, control group; SS, Se supplemented group; $\mathrm{SD}$, Se deficient group. Significance: C vs SD, ${ }^{*} P<0.05$; SS vs SD, ${ }^{\sharp} P<0.05$. 


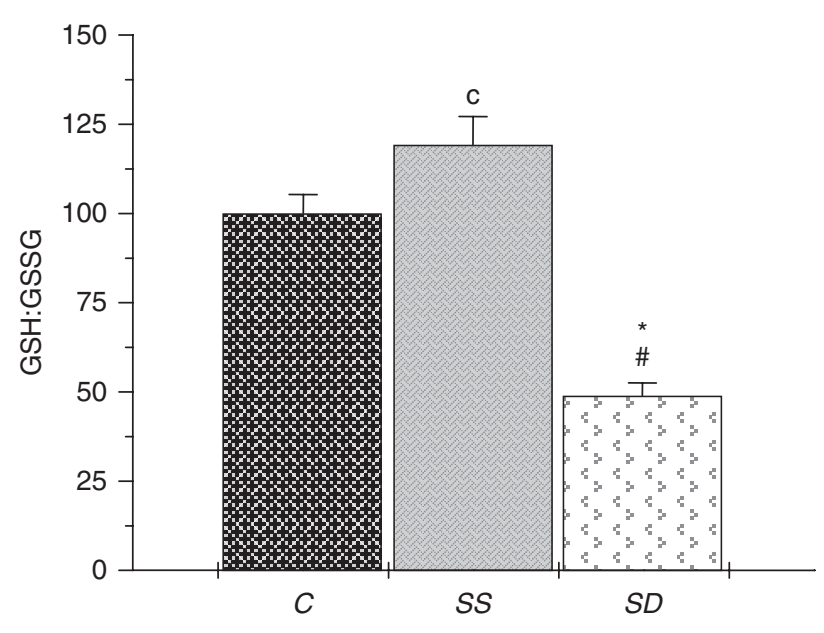

Figure $4 \mathrm{GSH}$ :GSSG ratio in offspring. The results are expressed as mean \pm S.E.M. and analyzed by a multifactorial ANOVA (one-way ANOVA) followed by the Tukey's test. The number of animals in each group is 8. Groups: C, control group; SS, Se supplemented group; SD, Se deficient group. Significance: $\mathrm{C}$ vs SS, ${ }^{\mathrm{C}} P<0.05 ; \mathrm{C}$ vs SD, ${ }^{*} P<0.001$; SS vs $\mathrm{SD},{ }^{\sharp} P<0.001$.

promoting growth and development of the offspring and protecting them from oxidative stress.

\section{Selenoprotein expression}

Selenoprotein synthesis is highly dependent on Se, and there is a hierarchy of selenoprotein expression in mammals when Se is limited (Driscoll \& Copeland 2003); thus, a competition for translation exits between selenoproteins (Schomburg \& Schweizer 2009). However, little is known about the expression of the selenoprotein GPx in the offspring of rats that receive a different Se content in their diets during gestation and lactation. The main GPx isoforms delivered in liver are GPx1 and GPx4 (Hoffmann et al. 2007; Figs 5 and 6). In this study, GPx1 expression in offspring also responded to Se concentration in diet and in liver, coinciding with liver GPx activity (Figs 5A and 6). Thus, SD pups expressed a very low amount of GPx 1 vs $C$ ones, and SS expressed a higher amount than $\mathrm{C}$ ones. It is deduced that dietary Se provokes down/upregulations in Se liver deposits, GPx activity, and GPx1 expression. These results agree partially with the results of other authors in adult rats after Se deprivation (Sunde \& Raines 2011, Liu et al. 2012). Taking all these data into account, it could be suggested that the antioxidant activity determined in the liver of pups depends primarily on GPx1 expression.

The isoform GPx4 presents specific and essential functions for life, as it is the only GPx enzyme that is able to reduce hydroperoxides within membranes, avoiding membrane oxidation (Brigelius-Flohé \& Maiorino 2013). In this study, GPx4 expression also decreased in SD pups; however, this decrease was lower than that found in GPx1 expression (Figs 5B and 6). By contrast, SS pups expressed more GPx4 than C ones, but this increase was proportionally much higher than that observed in GPx 1 expression. Analyzing these results, we conclude that, in nursing pups, GPx4 is preferentially sustained in comparison to GPx1, as is the case in adult rats (Sunde \& Raines 2011). Thus, as in adult animals, selenoproteins featured a different degree of Se dependence for their biosynthesis in pups, probably related to the physiological importance of each protein (Schomburg \& Schweizer 2009). As GPx4 acts protecting against oxidation of the membrane phospholipids, it could play an important role during lactation (when there is an intense phase of cell formation), protecting the newly synthesized phospholipids. Taking into account that in this period of life the amount of phospholipid vs triglycerides is higher, the lipid profile is different to that found in adulthood (Ojeda et al. 2008); the increase in GPx4 could be related to the absence of lipid oxidation in the groups studied. Based on this information, it can be concluded that GPx1 is very sensitive, and GPx4 is highly resistant, to dietary Se deficiency in offspring, and according to this, as GPx1 expression is fully committed, in SD pups protein oxidation occurs; however, as GPx4 expression is not completely decreased, phospholipid

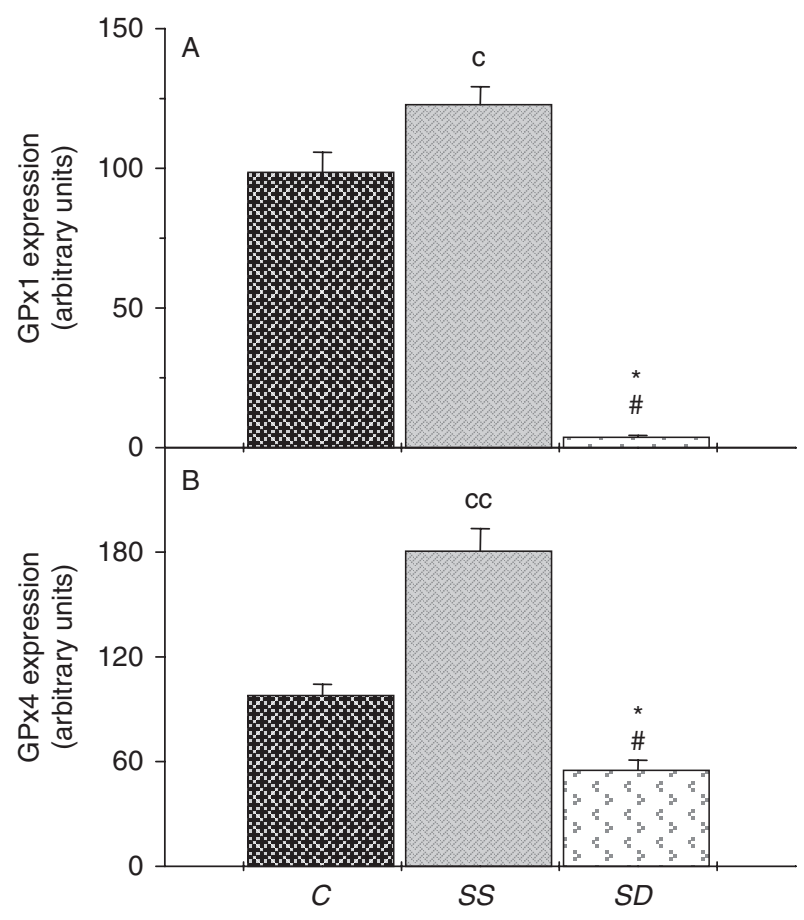

Figure 5 Hepatic selenoproteins GPx1 (A) and GPx4 (B) expression in offspring. The results are expressed as mean \pm S.E.M. and analyzed by a multifactorial ANOVA (one-way ANOVA) followed by the Tukey's test. The number of animals in each group is 8 . Groups: C, control group; SS, Se supplemented group; SD, Se deficient group. Signification: $C$ vs SS: ${ }^{\mathrm{cc}} P<0.001,{ }^{\mathrm{c}} P<0.05 ;$ C vs SD: ${ }^{*} P<0.001$; SS vs SD: ${ }^{\sharp} P<0.001$. 


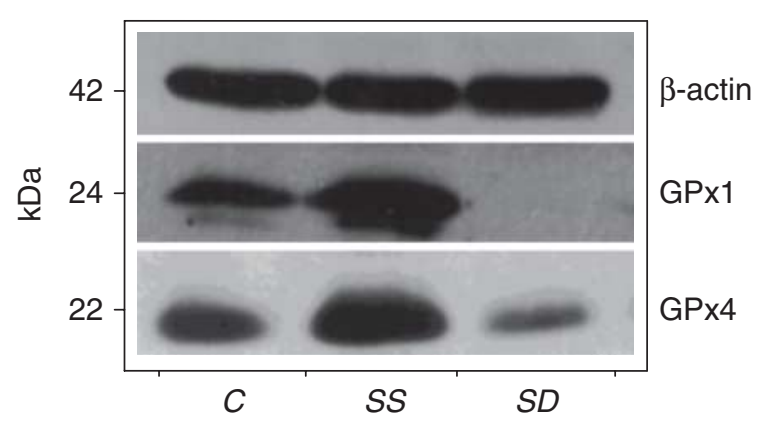

Figure 6 Hepatic selenoproteins GPx1 and GPx4 expression in offspring.

oxidation does not take place. This resistance of GPx4 is probably due to having an important physiological function in these pups, as Brigelius-Flohé \& Maiorino (2013) described in their review, a knockout of GPx4 is the only knockout of a GPx that is embryonically lethal; therefore, GPx4 cannot simply be an antioxidant enzyme but must have specific functions that are essential for life and cell proliferation, and in the SD pups of this study is decreased.

\section{Conclusions}

In conclusion, maternal Se intake during gestation and lactation alters offspring oxidative response and development. This effect is related to Se liver deposits and, in part, to GPx activity, which primarily depends on GPx1 expression and secondly to GPx4. When Se is supplemented in diet, pup development is improved as antioxidant enzymes are overexpressed, avoiding the oxidative action of somatic growth. When the Se supply is deficient, intrauterine growth retardation appeared together with a higher risk of death during lactation. In this case, Se is depleted in liver, GPx activity decreased, and protein oxidation appeared. These effects are linked to an almost total suppression of GPx 1 expression and to a partial of the GPx4. If a risk of uterine growth retardation is suspected, or neonates with low birth weight present signs of liver oxidation, knowledge about their Se status may be of great benefit. In conclusion, Se supplementation could be proposed as an antioxidant therapy during pregnancy and lactation promoting growth and development of the offspring and protecting them from oxidative stress.

\section{Declaration of interest}

The authors declare that there is no conflict of interest that could be perceived as prejudicing the impartiality of the research reported.

\section{Funding}

Grants from Ministerio de Sanidad, Fondo de Investigación Sanitaria (FIS, PI060335), supported this work.

\section{References}

Abd El-Ghany H, López-Arellano AE, Revilla-Vázquez R, RamírezBribiesca A \& Tórtora-Pérez EJ 2008 Effect of pre- and pospartum selenium supplementation in sheep. Journal of Animal and Veterinary Advances 7 61-67.

Aksu I, Baykara B, Kiray M, Gurpinar T, Sisman AR, Ekerbicer N, Tas A, Gokdemir-Yazar O \& Uysal N 2013 Serum IGF-1 levels correlate negatively to liver damage in diabetic rats. Biotechnic \& Histochemistry 88 194-201. (doi:10.3109/10520295.2012.758311)

Agay D, Sandre C, Ducros V, Faure H, Cruz C, Alonso A, Roussel AM \& Chancerelle Y 2005 Optimization of selenium status by a single intraperitoneal injection of Se in Se-deficient rat: possible application to burned patient treatment. Free Radical Biology \& Medicine 39 762-768. (doi:10.1016/j.freeradbiomed.2005.04.024)

Ahmad H, Tian J, Wang J, Khan MA, Wang Y, Zhang L \& Wang T 2012 Effects of dietary sodium selenite and selenium yeast on antioxidant enzyme activities and oxidative stability of chicken breast meat. Journal of Agricultural and Food Chemistry 60 7111-7120. (doi:10. 1021/jf3017207)

Avanzo JL, Mendonca CX, Pugine SM \& Cesar MC 2001 Effect of vitamin E and selenium on resistance to oxidative stress in chicken superficial pectoralis muscle. Comparative Biochemistry and Physiology. Part C, Toxicology \& Pharmacology 129 163-173. (doi:10.1016/S15320456(01)00197-1)

Aydin K, Bideci A, Kendirci M, Cinaz P \& Kurtoglu S 2002 Insulin-like growth factor-I and insulin-like growth factor binding protein-3 levels of children living in an iodine- and selenium-deficient endemic goiter area. Biological Trace Element Research 90 25-30. (doi:10.1385/BTER:90: 1-3:25)

Beers RF \& Sizer IW 1952 A spectrophotometric method for measuring the breakdown of hydrogen peroxide by catalase. Journal of Biological Chemistry 1 133-140.

Biri A, Bozkurt N, Turp A, Kavutcu M, Himmetoglu O \& Durak I 2007 Role of oxidative stress in intrauterine growth restriction. Gynecologic and Obstetric Investigation 64 187-192. (doi:10.1159/000106488)

Brigelius-Flohé R \& Maiorino M 2013 Glutathione peroxidases. Biochimica et Biophysica Acta 1830 3289-3303. (doi:10.1016/j.bbagen.2012.11. 020)

Brown-Borg HM, Rakoczy SG, Romanick MA \& Kennedy MA 2002 Effects of growth hormone and insulin-like growth factor-1 on hepatocyte antioxidative enzymes. Experimental Biology and Medicine 227 94-104.

Cole-Ezea P, Swan D, Shanley D \& Hesketh J 2012 Glutathione peroxidase 4 has a major role in protecting mitochondria from oxidative damage and maintaining oxidative phosphorylation complexes in gut epithelial cells. Free Radical Biology \& Medicine 53 488-497. (doi:10.1016/j.freeradbiomed.2012.05.029)

Draper HH \& Hadley M 1990 Malondialdehyde determination as index of lipid peroxidation. Methods in Enzymology 186 421-431.

Driscoll DM \& Copeland PR 2003 Mechanism and regulation of selenoprotein synthesis. Annual Review of Nutrition 23 17-40. (doi:10. 1146/annurev.nutr.23.011702.073318)

Erkekoglu P, Giray BK, Kızilgün M, Rachidi W, Hininger-Favier I, Roussel AM, Favier A \& Hincal F 2012 Di(2-ethylhexyl)phthalateinduced renal oxidative stress in rats and protective effect of selenium. Toxicology Mechanisms and Methods 22 415-423. (doi:10.3109/ 15376516.2012.666652)

Fridovich I 1985 Cytochrome $c$. In CRC Handbook of Methods for Oxygen Radical Research, pp 213-215. Ed. RA Greenwald. Boca Raton, Florida: CRC Press.

Gunter SA, Beck PA \& Hallford DM 2013 Effects of supplementary selenium source on the blood parameters in beef cows and their nursing calves. Biological Trace Element Research 152 204-211. (doi:10.1007/s12011013-9620-0) 
Hracsko Z, Orvos H, Novak Z, Pal A \& Varga IS 2008 Evaluation of oxidative stress markers in neonates with intra-uterine growth retardation. Redox Report 13 11-16. (doi:10.1179/135100008X259097)

He JH, Cao MH, Gao FX, Wang JH \& Hayashi K 2006 Dietary thyroid hormone improves growth and muscle protein accumulation of blackboned chickens. British Poultry Science 47 567-571. (doi:10.1080/ 00071660600953835)

Hefnawy AEG \& Tórtora-Pérez JL 2010 The importance of selenium and the effects of its deficiency in animal health. Small Ruminant Research $\mathbf{8 9}$ 185-192. (doi:10.1016/j.smallrumres.2009.12.042)

Hoffman DJ 2002 Role of selenium toxicity and oxidative stress in aquatic birds. Aquatic Toxicology 57 11-26. (doi:10.1016/S0166-445X(01) 00263-6)

Hoffmann PR, Höge SC, Li PA, Hoffmann FW, Hashimoto AC \& Berry MJ 2007 The selenoproteome exhibits widely varying, tissue-specific dependence on selenoprotein P for selenium supply. Nucleic Acids Research 35 3963-3973. (doi:10.1093/nar/gkm355)

Karl JP, Alemany JA, Koenig C, Kraemer WJ, Frystyk J, Flyvbjerg A, Young AJ \& Nindl BC 2009 Diet, body composition, and physical fitness influences on IGF-I bioactivity in women. Growth Hormone \& IGF Research 19 491-496. (doi:10.1016/j.ghir.2009.04.001)

Lawrence RA \& Burk RF 1976 Glutathione peroxidase activity in seleniumdeficient rat liver. Biochemical and Biophysical Research Communications 71 952-958. (doi:10.1016/0006-291X(76)90747-6)

Liu Y, Zhao H, Zhang Q, Tang J, Li K, Xia XJ, Wang KN, Li K \& Lei XG 2012 Prolonged dietary selenium deficiency or excess does not globally affect selenoprotein gene expression and/or protein production in various tissues of pigs. Journal of Nutrition 142 1410-1416. (doi:10.3945/jn.112. 159020)

Lowry OH, Rosebrough NJ, Farr AL \& Randall RJ 1951 Protein measurement with the Folin phenol reagent. Journal of Biological Chemistry 1 265-275.

Maggio M, Ceda GP, Lauretani F, Bandinelli S, Dall'aglio E, Guralnik JM, Paolisso G, Semba RD, Nouvenne A, Borghi L et al. 2010 Association of plasma selenium concentrations with total IGF-1 among older community-dwelling adults: the InCHIANTI study. Clinical Nutrition 29 674-677. (doi:10.1016/j.clnu.2010.03.012)

Mehta SL, Kumari S, Mendelev N \& Li PA 2012 Selenium preserves mitochondrial function, stimulates mitochondrial biogenesis, and reduces infarct volume after focal cerebral ischemia. BMC Neuroscience 9 13-79. (doi:10.1186/1471-2202-13-79)

Miell JP, Taylor AM, Zini M, Maheshwari HG, Ross RJ \& Valcavi R 1993 Effects of hypothyroidism and hyperthyroidism on insulin-like growth factors (IGFs) and growth hormone- and IGF-binding proteins. Journal of Clinical Endocrinology and Metabolism 76 950-955. (doi:10.1210/jc. 76.4.950)

Mistry HD, Broughton Pipkin F, Redman CW \& Poston L 2012 Selenium in reproductive health. American Journal of Obstetrics and Gynecology 206 21-30. (doi:10.1016/j.ajog.2011.07.034)

Moreno-Reyes R, Egrise D, Nève J, Pasteels JL \& Schoutens A 2001 Selenium deficiency-induced growth retardation is associated with an impaired bone metabolism and osteopenia. Journal of Bone and Mineral Research 16 1556-1563. (doi:10.1359/jbmr.2001.16.8.1556)

Ojeda ML, Delgado-Villa MJ, Llopis R, Murillo ML \& Carreras O 2008 Lipid metabolism in ethanol-treated rat pups and adults: effects of folic acid. Alcohol and Alcoholism 43 544-550. (doi:10.1093/alcalc/agn044)

Ojeda ML, Nogales F, Vázquez B, Delgado MJ, Murillo ML \& Carreras O 2009 Alcohol, gestation and breastfeeding: selenium as an antioxidant therapy. Alcohol and Alcoholism 44 272-277. (doi:10.1093/alcalc/ agp004)

Ojeda ML, Nogales F, Murillo ML \& Carreras O 2012 Selenium or selenium plus folic acid-supplemented diets ameliorate renal oxidation in ethanolexposed pups. Alcoholism, Clinical and Experimental Research 36 1863-1872. (doi:10.1111/j.1530-0277.2012.01788.x)

Papp LV, Lu J, Holmgren A \& Khanna KK 2007 From selenium to selenoproteins: synthesis, identity, and their role in human health. Antioxidants \& Redox Signaling 9 775-806. (doi:10.1089/ars.2007.1528)
Parízek J 1990 Health effects of dietary selenium. Food and Chemical Toxicology 28 763-765. (doi:10.1016/0278-6915(90)90075-X)

Pathak R, Mustafa MD, Ahmed T, Ahmed RS, Tripathi AK, Guleria K \& Banerjee BD 2011 Intra uterine growth retardation: association with organochlorine pesticide residue levels and oxidative stress markers. Reproductive Toxicology 31 534-539. (doi:10.1016/j.reprotox. 2011.02.007)

Payne RL \& Southern LL 2005 Changes in glutathione peroxidase and tissue selenium concentrations of broilers after consuming a diet adequate in selenium. Poultry Science 84 1268-1276.

Ramírez BJE, Tórtora JL, Hernández LM \& Huerta M 2001 Main causes of mortalities in dairy goat kids from the Mexican plateau. Small Ruminant Research 41 77-80.

Rayman MP 2012 Selenium and human health. Lancet 379 1256-1268. (doi:10.1016/S0140-6736(11)61452-9)

Reznick AZ \& Packer L 1994 Oxidative damage to proteins: spectrophotometric method for carbonyl assay. Methods in Enzymology 233 357-363. (doi:10.1016/S0076-6879(94)33041-7)

Richie JP Jr, Das A, Calcagnotto AM, Aliaga CA \& El-Bayoumy K 2012 Age related changes in selenium and glutathione levels in different lobes of the rat prostate. Experimental Gerontology 47 223-228. (doi:10.1016/j. exger.2011.11.015)

Schomburg L \& Schweizer U 2009 Hierarchical regulation of selenoprotein expression and sex-specific effects of selenium. Biochimica et Biophysica Acta 1790 1453-1462. (doi:10.1016/j.bbagen.2009.03.015)

Shi D, Guo S, Liao S, Su R, Pan J, Lin Y \& Tang Z 2012 Influence of selenium on hepatic mitochondrial antioxidant capacity in ducklings intoxicated with aflatoxin B? Biological Trace Element Research 145 325-329. (doi:10.1007/s12011-011-9201-z)

Stỳblo M, Walton FS, Harmon AW, Sheridan PA \& Beck MA 2007 Activation of superoxide dismutase in selenium-deficient mice infected with influenza virus. Journal of Trace Elements in Medicine and Biology 21 52-62. (doi:10.1016/j.jtemb.2006.11.001)

Sirota TV 2010 Effect of selenium-containing products on antioxidant enzyme activity in the kidneys, liver, and blood of guinea pigs. Bulletin of Experimental Biology and Medicine 149 412-415. (doi:10.1007/ s10517-010-0958-4)

Subramanian MG 1995 Effects of chronic alcohol administration on lactational performance in the rat. Alcohol 12 137-143. (doi:10.1016/ 0741-8329(94)00073-5)

Sunde RA \& Raines AM 2011 Selenium regulation of the selenoprotein and nonselenoprotein transcriptomes in rodents. Advances in Nutrition 2 138-150. (doi:10.3945/an.110.000240)

Turło J, Gutkowska B \& Herold F 2010 Effect of selenium enrichment on antioxidant activities and chemical composition of Lentinula edodes (Berk.) Pegl. mycelial extracts. Food and Chemical Toxicology 48 1085-1091. (doi:10.1016/j.fct.2010.01.030)

Wang Y, Wu Y, Luo K, Liu Y, Zhou M, Yan S, Shi H \& Cai Y 2013 The protective effects of selenium on cadmium-induced oxidative stress and apoptosis via mitochondria pathway in mice kidney. Food and Chemical Toxicology 58C 61-67. (doi:10.1016/j.fct.2013.04.013)

Ward MA, Neville TL, Reed JJ, Taylor JB, Hallford DM, Soto-Navarro SA, Vonnahme KA, Redmer DA, Reynolds LP \& Caton JS 2008 Effects of selenium supply and dietary restriction on maternal and fetal metabolic hormones in pregnant ewe lambs. Journal of Animal Science $\mathbf{8 6}$ 1254-1262. (doi:10.2527/jas.2007-0509)

Worthington DJ \& Rosemeyer MH 1974 Human glutathione reductase: purification of the crystalline enzyme from erythrocytes. European Journal of Biochemistry 48 167-177. (doi:10.1111/j.1432-1033.1974. tb03754.x)

Received 19 June 2013

First decision 13 September 2013

Revised manuscript received 19 September 2013

Accepted 30 September 2013 